\title{
Perbandingan Bupivakain 0,25\% dengan Kombinasi Bupivakain 0,25\% dan Deksametason 8 mg pada Blok Transversus Abdominis Plane dengan Panduan Ultrasonografi sebagai Analgesia Pascahisterektomi
}

\author{
Eddo Alan Delis, ${ }^{1}$ Dedi Fitri Yadi, ${ }^{2}$ Erwin Pradian $^{2}$ \\ ${ }^{1}$ RSUD R. Syamsudin, SH, Sukabumi, ${ }^{2}$ Departemen Anestesiologi dan Terapi Intensif \\ Fakultas Kedokteran Universitas Padjadjaran/RSUP Dr. Hasan Sadikin Bandung
}

\begin{abstract}
Abstrak
Analgesia dinding abdomen anterior dan lateral dapat dilakukan dengan blok transversus abdominis plane (TAP). Penelitian ini bertujuan menilai waktu kebutuhan analgesik pertama dan skor nyeri 2, 4, 6, 12, 24 jam pascahisterektomi antara bupivakain 0,25\% dengan kombinasi bupivakain 0,25\% dan deksametason $8 \mathrm{mg}$ pada blok TAP. Penelitian menggunakan uji klinis acak terkontrol buta tunggal, dilakukan di Rumah Sakit Dr. Hasan Sadikin (RSHS) Bandung pada bulan Oktober-Desember 2017. Pasien dibagi menjadi grup bupivakain $0,25 \%$ (grup $B, n=20$ ) dan grup kombinasi bupivakain 0,25\% deksametason 8 mg (grup BD, $n=20$ ). Uji statistik menggunakan uji-t berpasangan, Uji Wilcoxon, dan uji chi-square. Hasil penelitian mengungkapkan waktu kebutuhan analgesik pertama lebih lama pada grup BD $(866,45 \pm 98,11$ menit) dibanding dengan grup B $(352,75 \pm 43,32$ menit) dengan perbedaan signifikan $(\mathrm{p}<0,05)$. Median skor nyeri pascahisterektomi grup BD pada 4 jam (1), 6 jam (2), 12 jam (2), dan 24 jam (2) lebih rendah dibanding dengan grup B dengan median skor nyeri 4 jam (2), 6 jam (3), 12 jam (4), dan 24 jam (3), dengan perbedaan signifikan $(\mathrm{p}<0,05)$. Simpulan penelitian ini adalah kombinasi bupivakain $0,25 \%$ dan deksametason 8 mg pada blok TAP menghasilkan waktu kebutuhan analgesik pertama lebih lama dan skor nyeri pascahisterektomi lebih rendah dibanding dengan bupivakain $0,25 \%$.
\end{abstract}

Kata kunci: Blok transversus abdominis plane, deksametason, skor nyeri, waktu kebutuhan analgesik pertama

\section{Comparison between $0.25 \%$ Bupivacaine and Combination of $0.25 \%$ Bupivacaine and $8 \mathrm{mg}$ Dexamethasone on Transversus Abdominis Plane Block Ultrasound-guided as Post- Hysterectomy Analgesia}

\begin{abstract}
Analgesia for anterior and lateral abdominal walls can be provided through transversus abdominis plane (TAP) block. This study aimed to evaluate the timing of first analgesic requirement and post- hysterectomy pain scores at 2, 4, 12, 24 hours between $0.25 \%$ bupivacaine and combination of $0.25 \%$ bupivacaine and 8 mg dexamethasone on TAP block. This was a randomized single-blind controlled trial study on patients Dr. Hasan Sadikin Hospital (RSHS) Bandung in the period of October-December 2017. Patients were randomly divided into $0.25 \%$ bupivacaine (B group, $\mathrm{n}=20$ ) and $00.25 \%$ bupivacaine $8 \mathrm{mg}$ dexamethasone combination (BD group, $n=20$ ). Statistical test was performed using paired $t$ test, Wilcoxon test, and chi-square test. It was revealed that the time to first analgesic requirement was longer in BD group (866.45 \pm 98.11 minutes) than in B group (352.75 \pm 43.32 minutes) with a significant difference $(\mathrm{p}<0.05)$. The post-hysterectomy pain score medians in BD group at 4 hours (1), 6 hours (2), 12 hours (2), and 24 hours (2) were lower than those of B group with a significant difference $(\mathrm{p}<0.05)$. Therefore, $0.25 \%$ bupivacaine and $8 \mathrm{mg}$ dexamethasone combination for ultrasound-guided TAP block presents longer time to first analgesic requirement and lower pain score compared to $0.25 \%$. bupivacaine
\end{abstract}

Key words: Dexamethasone, pain score, time to first analgesic requirement, transversus abdominis plane block

Korespondensi: Eddo Alan Delis, dr., SpAn, RSUD R. Syamsudin, SH, l. Rumah Sakit No.1, Cikole, Kota Sukabumi, Jawa Barat 43113, Tlpn (0266) 225180, Email eddoalan@gmail.com 


\section{Pendahuluan}

Histerektomi adalah pengangkatan uterus melalui prosedur pembedahan. Prosedur ini dilakukan pada tumor organ reproduksi wanita dan berbagai kondisi nonkanker seperti fibroid, endometriosis, adenomiosis, prolaps uterus, dan perdarahan uterus disfungsi. ${ }^{1}$

Insisi abdomen yang dilakukan pada histerektomi menghasilkan nyeri pascabedah dengan kategori berat. ${ }^{2}$ Proporsi terbanyak penyebab nyeri ini berhubungan dengan nyeri somatis yang berasal dari dinding abdomen. ${ }^{3}$

Terapi nyeri derajatsedang-beratumumnya diberikan opioid, akan tetapi pemberian opioid dapat menimbulkan efek samping berupa sedasi, mual, dan muntah sehingga diperlukan metode untuk menurunkan konsumsi opioid serta mengurangi efek sampingnya. ${ }^{2}$ Efek samping pemberian opioid dapat dikurangi dengan teknik multimodal, yaitu memberikan dua atau lebih obat dengan mekanisme kerja yang berbeda. Menurut the American Society of Anesthesiologists (ASA), blok saraf memakai anestetik lokal dianjurkan sebagai bagian dari teknik multimodal untuk manajemen nyeri. ${ }^{4}$

Blok saraf dengan infiltrasi anestetik lokal pada daerah insisi dapat digunakan untuk mengurangi impuls saraf di daerah tersebut. Tindakan tersebut dapat menimbulkan seperti menurunkan produksi kolagen, menurunkan kekuatan otot, dan menyebabkan edema yang akhirnya mengganggu proses penyembuhan luka. ${ }^{5}$

Metode blok saraf perifer lain yang dapat digunakan adalah blok transversus abdominis plane (TAP). Blok TAP menempatkan anestetik lokal di antara otot oblikus interna dan otot transversus abdominis sehingga dapat menghambat saraf sensoris dinding abdomen dari torakal 6 sampai lumbal $1 .^{3}$ Penelitian meta-analisis mengenai efektivitas blok TAP pascahisterektomi menyatakan bahwa blok TAP mengurangi skor nyeri dan konsumsi opioid dalam 24 jam pascahisterektomi. ${ }^{6}$

Blok saraf perifer menghasilkan kontrol nyeri yang baik dengan efek samping rendah. Hanya saja pada blok saraf perifer dengan teknik single-injection memiliki keterbatasan dalam hal lama kerja analgesia. ${ }^{7}$ Hal tersebut dapat diatasi dengan memberikan adjuvan pada anestetik lokal untuk memperpanjang lama kerja analgesia. Adjuvan yang digunakan untuk memperpanjang lama kerja obat anestesi lokal misalnya epinefrin dan klonidin, sedangkan untuk potensiasi analgesia dapat diberikan deksmedetomidin, buprenorfin, dan tramadol. Pada penelitian tersebut dipilih deksametason sebagai adjuvan karena dapat memperpanjang lama kerja dan potensiasi analgesia dari anestetik lokal. ${ }^{8}$

Penambahan deksametason pada anestetik lokal telah dilakukan pada beberapa penelitian yang membuktikan bahwa waktu kebutuhan analgesik pertama lebih panjang dan skor nyeri lebih rendah pada grup deksametason dibanding dengan grup kontrol. ${ }^{3,9}$ Penelitian ini bertujuan untuk membandingkan waktu kebutuhan analgesik pertama dan skor nyeri antara blok TAP panduan ultrasonografi memakai bupivakain $0,25 \%$ dengan kombinasi bupivakain $0,25 \%$ dan deksametason $8 \mathrm{mg}$.

\section{Subjek dan Metode}

Penelitian ini merupakan uji klinis acak terkontrol buta tunggal yang dilakukan pada bulan Oktober sampai Desember 2017 di Central Operating Theatre (COT) dan ruang perawatan Rumah Sakit Umum Pusat Dr. Hasan Sadikin Bandung (RSHS).

Kriteria inklusi subjek penelitian adalah pasien yang menjalani prosedur histerektomi, usia 18-65 tahun, status fisik American Society of Anesthesiologists (ASA) I-II, dan indeks massa tubuh (IMT) 18,5-29,9 kg/ $\mathrm{m}^{2}$. Kriteria eksklusi, yaitu subjek menolak untuk dilakukan blok TAP, infeksi kulit dinding abdomen di lokasi suntikan blok TAP, serta alergi terhadap anestetik lokal dan obatobatan yang digunakan dalam penelitian. Kriteria pengeluaran adalah gagal blok TAP bila pasien masih merasakan sakit setelah dilakukan pin-prick di dermatom torakal 6 sampai lumbal 1.

Jumlah sampel ditentukan berdasar atas rumus untuk menguji perbedaan dua rerata dengan taraf kepercayaan 95\% dan power 
test $90 \%$. Berdasar atas perhitungan tersebut diperoleh jumlah sampel minimal untuk tiaptiap kelompokadalah 18 pasien, ditambah $10 \%$ kemungkinan pengeluaran sampel sehingga jumlah sampel tiap kelompoknya adalah 20 dan jumlah sampel sebesar 40 pasien.

Pemilihan subjek penelitian berdasar atas consecutive sampling, yaitu mengambil setiap subjek penelitian yang memenuhi kriteria inklusi berdasar atas urutan kedatangan. Randomisasi pada subjek penelitian dilakukan menggunakan metode blok permutasi menjadi dua kelompok, yaitu kelompok bupivakain (B) dengan kelompok kombinasi bupivakain dan deksametason (BD).
Penelitian dilakukan setelah mendapatkan persetujuan Komite Etik Penelitian Kesehatan Fakultas Kedokteran Universitas Padjadjaran/ RSHS. Pasien yang memenuhi kriteria inklusi dan tidak termasuk kriteria eksklusi diberikan penjelasan tentang penelitian dan diukur skor cemas menggunakan skala HARS. Lorazepam 0,03-0,05 mg/kgBB per oral diberikan 2 jam sebelum operasi. Seluruh pasien diberikan anestesi umum. Satu jam sebelum tindakan histerektomi selesai diberikan ketorolak 30 mg intravena dan dilanjutkan setiap 8 jam selama 24 jam. Setelah histerektomi selesai dilakukan blok TAP panduan ultrasonografi, kelompok B menggunakan $20 \mathrm{~mL}$ bupivakain

Tabel 1 Karakteristik Subjek Penelitian

\begin{tabular}{|c|c|c|c|}
\hline \multirow[b]{2}{*}{ Variabel } & \multicolumn{2}{|c|}{ Kelompok } & \multirow[b]{2}{*}{ Nilai p } \\
\hline & $\begin{array}{c}B \\
(n=20)\end{array}$ & $\begin{array}{c}\text { BD } \\
(n=20)\end{array}$ & \\
\hline Usia (tahun) & & & 0,96 \\
\hline Rerata (SD) & $48,55 \pm 6,87$ & $48,45 \pm 5,95$ & \\
\hline Rentang & $34-59$ & $36-59$ & \\
\hline Berat badan $(\mathrm{kg})$ & & & 0,93 \\
\hline Rerata (SD) & $59,12 \pm 4,74$ & $59,25 \pm 3,62$ & \\
\hline Rentang & $47,5-65$ & $50-64$ & \\
\hline Indeks massa tubuh $\left(\mathrm{kg} / \mathrm{m}^{2}\right)$ & & & 0,2 \\
\hline Rerata (SD) & $24,4 \pm 3,07$ & $25,6 \pm 2,81$ & \\
\hline Rentang & $17,5-28,4$ & $20-30$ & \\
\hline Status fisik ASA & & & 0,74 \\
\hline I & $7(35 \%)$ & $6(30 \%)$ & \\
\hline II & $13(65 \%)$ & $14(70 \%)$ & \\
\hline \multicolumn{4}{|l|}{ Skor cemas (HARS) } \\
\hline Median & 8 & 8 & 0,8 \\
\hline Rentang & $4-12$ & $5-12$ & \\
\hline Tingkat pendidikan & & & 1 \\
\hline SD & 1 & 3 & \\
\hline SMP & 2 & 0 & \\
\hline SMA & 16 & 17 & \\
\hline PT & 1 & 0 & \\
\hline
\end{tabular}

Keterangan: Data usia, berat badan dan indeks massa tubuh diuji dengan uji t tidak berpasangan, data skor cemas menggunakan Uji Mann Whitney. Data status fisik ASA menggunakan uji chi-square, data tingkat pendidikan menggunakan Uji Kolmogorov Smirnov 
Tabel 2 Perbandingan Waktu Kebutuhan Analgesik Pertama

\begin{tabular}{lccc}
\hline \multirow{2}{*}{ Waktu Kebutuhan Analgesik Pertama (menit) } & \multicolumn{3}{c}{ Kelompok } \\
\cline { 2 - 4 } & $\mathbf{B}$ & $\mathbf{B}$ & Nilai p \\
\hline Rerata (SD) & $352,75 \pm 43,32$ & $866,45 \pm 98,11$ & 0,00 \\
Rentang & $286-448$ & $689-1037$ & \\
\hline
\end{tabular}

Keterangan: Data diuji dengan uji t tidak berpasangan. Nilai kemaknaan berdasarkan nilai $\mathrm{p}<0,05$ yang artinya signifikan atau bermakna secara statistik

$0,25 \%$ pada kedua sisi abdomen, sedangkan kelompok BD menggunakan kombinasi bupivakain $0,25 \%$ dan deksametason $8 \mathrm{mg}$. Kemudian, dilakukan ekstubasi dan pasien dipindahkan ke ruang pemulihan. Patient controlled analgesia (PCA) morfin diberikan di ruang pemulihan dengan dosis bolus $1 \mathrm{mg}$, lockout interval 10 menit dan dosis maksimal dalam 4 jam adalah $20 \mathrm{mg}$. Data yang dicatat adalah waktu kebutuhan analgesik pertama yang dimulai setelah injeksi komplit bilateral blok TAP serta skor nyeri pada jam ke-2, 4, 6, 12, dan 24 jam pascahisterektomi.
Pada penelitian ini, uji statistik untuk data numerik menggunakan uji-t berpasangan apabila data berdistribusi normal dan uji Wilcoxon apabila data tidak berdistribusi normal. Analisis statistik untuk data kategorik menggunakan uji chi-square. Data dicatat dalam formulir khusus kemudian diolah menggunakan program statistical product and service solutions (SPSS) versi 24.0 for windows.

\section{Hasil}

Gambaran karakteristik subjek penelitian

Tabel 3 Perbandingan Skor Nyeri Pascahisterektomi

\begin{tabular}{|c|c|c|c|}
\hline \multirow[b]{2}{*}{ Variabel } & \multicolumn{2}{|c|}{ Kelompok } & \multirow[b]{2}{*}{ Nilai p } \\
\hline & $\begin{array}{c}B \\
(n=20)\end{array}$ & $\begin{array}{c}\text { BD } \\
(n=20)\end{array}$ & \\
\hline Skor nyeri 2 jam pascahisterektomi & & & 0,6 \\
\hline Median & 1 & 1 & \\
\hline Rentang & $1-2$ & $1-2$ & \\
\hline Skor nyeri 4 jam pascahisterektomi & & & 0,01 \\
\hline Median & 2 & 1 & \\
\hline Rentang & $1-3$ & $1-2$ & \\
\hline Skor nyeri 6 jam pascahisterektomi & & & 0,00 \\
\hline Median & 3 & 2 & \\
\hline Rentang & $2-4$ & $1-3$ & \\
\hline Skor nyeri 12 jam pascahisterektomi & & & 0,00 \\
\hline Median & 4 & 2 & \\
\hline Rentang & $2-4$ & $2-3$ & \\
\hline Skor nyeri 24 jam pascahisterektomi & & & 0,00 \\
\hline Median & 3 & 2 & \\
\hline Rentang & $2-5$ & $1-4$ & \\
\hline
\end{tabular}

Keterangan: Data diuji dengan Uji Mann Whitney 
Tabel 4 Perbandingan Total Kebutuhan Opioid dalam 24 Jam

\begin{tabular}{lccc}
\hline \multirow{2}{*}{ Total Kebutuhan Opioid dalam 24 Jam (mg) } & \multicolumn{2}{c}{ Kelompok } & \multirow{2}{*}{ Nilai p } \\
\cline { 2 - 3 } & $\begin{array}{c}\mathbf{B} \\
(\mathbf{n = 2 0})\end{array}$ & $\begin{array}{c}\mathbf{B D} \\
(\mathbf{n = 2 0})\end{array}$ & \\
\hline Median & 11 & 3 & 0,00 \\
Rentang & $4-20$ & $1-6$ & \\
\hline
\end{tabular}

Keterangan: Untuk data numerik nilai p diuji dengan Uji Mann Whitney

berdasar atas usia, berat badan, indeks massa tubuh, status fisik ASA, skor cemas, dan tingkat pendidikan antara kedua kelompok tidak ada perbedaan bermakna ( $p>0,05$; Tabel 1 ).

Waktu kebutuhan analgesik pertama pada kelompok BD lebih panjang dibanding dengan kelompok B yang berbeda bermakna $(\mathrm{p}<0,05$; Tabel 2).

Skor nyeri 2 jam pascahisterektomi tidak tampak perbedaan antara kedua kelompok ( $>0$,05); sedangkan pada 4 jam, 6 jam, 12 jam, dan 24 jam pascahisterektomi didapatkan skor nyeri yang lebih rendah pada kelompok BD dibanding dengan kelompok $B$ yang berbeda signifikan ( $\mathrm{p}<0,05$; Tabel 3).

Kebutuhan total morfin selama 24 jam pascahisterektomi pada kelompok B lebih rendah dibanding dengan kelompok BD yang berbeda signifikan $(p<0,05$; Tabel 4$)$.

\section{Pembahasan}

Karakteristik umum terdiri atas usia, berat badan, indeks massa tubuh, status fisik ASA, skor cemas, dan tingkat pendidikan. Usia berpengaruh pada skala nyeri karena ambang batas nyeri akan meningkat selaras dengan bertambahnya usia. $^{10}$ Indeks massa tubuh dan status fisik ASA menentukan kebutuhan konsumsi opioid. ${ }^{11,12}$ Faktor psikologis yang dapat memengaruhi nyeri di antaranya adalah faktor kognitif atau pendidikan dan kecemasan. ${ }^{13}$ Karakteristik umum kedua kelompok berdasar atas usia, berat badan, indeks massa tubuh, status fisik ASA, skor cemas, dan tingkat pendidikan tidak terdapat perbedaan bermakna $(p>0,05)$ yang berarti karakteristik subjek penelitian homogen sehingga dapat dibandingkan.
Deksametason dapat menghasilkan efek memperpanjang lama kerja serta potensiasi analgesia dari anestetik lokal. ${ }^{8} \mathrm{Hal}$ ini dapat terjadi karena deksametason menimbulkan vasokonstriksi, anti- inflamasi, inhibisi ectopic neuronal discharge, dan meningkatkan inhibisi kanal potassium di nosiseptif serabut C.,14

Penelitian ini mengungkapkan bahwa waktu kebutuhan analgesik pertama pada kelompok BD lebih panjang dibanding dengan kelompok B $(p<0,05)$. Hal ini sejalan dengan beberapa penelitian lain yang menunjukkan waktu kebutuhan analgesik pertama lebih panjang pada blok TAP kombinasi bupivakain dan deksametason dibanding dengan bupivakain. ${ }^{3,9}$

Vasokonstriksi dapat terjadi karena efek glukokortikoid dalam memengaruhireaktivitas vaskular dengan cara menghambat produksi vasodilator seperti prostasiklin dan nitric oxide, potensiasi respons vasoaktif terhadap katekolamin melalui reseptor glukokortikoid, serta meningkatkan respons kortisol yang berhubungan dengan peningkatan sensitivitas kontraksi arteri. ${ }^{15}$ Efek vasokonstriksi tersebut menyebabkan penurunan absorpsi sistemik sehingga terjadi pemanjangan waktu blok saraf oleh anestetik lokal. ${ }^{16}$

Hasil penelitian ini mengungkapkan bahwa pada 2 jam pascahisterektomi tidak terdapat perbedaan skor nyeri pada kedua kelompok, sedangkan pada 4, 6, 12, dan 24 jam pascahisterektomi menghasilkan skor nyeri pada kelompok BD lebih rendah dibanding dengan kelompok $B(p<0,05)$. Hal ini ditunjang oleh total kebutuhan opioid yang lebih rendah pada kelompok BD dibanding dengan kelompok B $(p<0,05)$. Penelitian sebelumnya mengungkapkan hasil yang sama berupa 
berkurangnya skor nyeri pashisterektomi menggunakan blok TAP kombinasi bupivakain dan deksametason bila dibanding dengan bupivakain..$^{3,9}$

Inflamasi pada jaringan yang terluka akan mengeluarkan substansi inflamasi seperti leukotrien, sitokin, dan juga prostaglandin. Substansi inflamasi tersebut akan merangsang eksitabilitas serabut saraf $\mathrm{C}^{17}$ Impuls saraf yang menyebabkan sensasi nyeri dihasilkan oleh reseptor nyeri yang terletak pada akhiran saraf bebas atau nosiseptor dan memberikan jawaban terhadap rangsang nyeri.

Terdapat dua nosiseptor, yaitu A $\delta$ dan $C$, kedua jenis nosiseptor tersebut tersebar luas dalam dermis dan akhirannya menembus epidermis. Keduanya juga ditemukan pada struktur yang lebih dalam seperti sistem muskuloskeletal. Serabut nosiseptor C bersifat polimodal dan memberikan reaksi terhadap rangsangan mekanik, termal, dan kimia termasuk substansi-substansi inflamasi. ${ }^{18} \mathrm{Efek}$ anti-inflamasi deksametason menghambat pengeluaran substansi inflamasi sehingga rangsangan terhadap serabut saraf pun akan terhambat. ${ }^{17}$

Pada keadaan normal, potensial aksi saraf sensoris berasal dari akhiran saraf perifer dan konduksi ke sistem saraf pusat. Setelah terjadi luka atau inflamasi, saraf perifer menjadi sumber dari ectopic neuronal discharge. Ectopic neuronal discharge ini menyebabkan peningkatan rasa nyeri akibat perubahan transmisi sensoris. Aktivitas tersebut mungkin terjadi karena substansi excitatory seperti mediator inflamasi dan pelepasan chemokines dari sel saraf sekitarnya. ${ }^{18}$ Deksametason dapat memberikan efek inhibisi dari ectopic neuronal discharge karena efek anti-inflamasi yang menghambat mediator inflamasi.

Deksametason bekerja secara langsung terhadap serabut saraf melalui reseptor glukokortikoiod, memengaruhi fungsi dari kanal potasium. ${ }^{16,19}$ Transmisi impuls elektrik dalam membran sel merupakan dasar dari transduksi sinyal serabut saraf. Energi yang diperlukan untuk perambatan dan mempertahankan potensial elektrik terjadi karena perbedaan konsentrasi ion natrium dan potassium di intraseluler dan ekstraseluler. Konduksi impuls elektrik sepanjang serabut saraf ini dikenal sebagai potensial aksi. Potensial aksi ini diawali oleh depolarisasi akibat influx natrium yang cepat, kemudian influx natrium ini akan digantikan oleh efflux potassium atau disebut repolarisasi. ${ }^{20}$ Deksametason menyebabkan inhibisi kanal potassium sehingga repolarisasi terhambat dan potensial aksi tidak terjadi. ${ }^{16}$

\section{Simpulan}

Blok TAP panduan ultrasonografi kombinasi bupivakain $0,25 \%$ dan deksametason $8 \mathrm{mg}$ menghasilkan waktu kebutuhan analgesik pertama lebih panjang dan skor nyeri lebih rendah dibanding dengan bupivakain $0,25 \%$ pada pasien pascahisterektomi.

\section{Daftar Pustaka}

1. Yakasai A. Complications of hysterectomy: a review. BJS. 2013;9(2):78-87.

2. Gharaei H, Imani F, Almasi F, Solimani M. The effect of ultrasound-guided TAPB on pain management after total abdominal hysterectomy. Korean J Pain. 2013;26(4):374-8.

3. Ammar AS, Mahmoud KM. Effect of adding dexamethasone to bupivacaine on transversus abdominis plane block for abdominal hysterectomy: a prospective randomized controlled trial. Saudi J Anaesth. 2012;6(3):229-33.

4. Apfelbaum JL, Ashburn MA, Connis RT, Gan TJ, Nickinovich DG. Practice guidelines for acutepainmanagementintheperioperative setting. ASA. 2012;116(2):248-73.

5. Bhaskar SB. Case for local infiltration analgesia: is all the evidence in black and white?. Indian J Anaesth. 2015;59(1):1-4.

6. Champaneria R, Shah L, Geoghegan J, Gupta JK, Daniels JP. Analgesic effectiveness of transversus abdominis plane blocks after hysterectomy: a meta-analysis. Eur J Obstet Gynecol Reprod Biol. 2013;166:1-9.

7. Macres SM, Moore PG, Fishman SM. Acute pain management. Dalam: Barash 
Eddo Alan Delis, Dedi Fitri Yadi, Erwin Pradian: Perbandingan Bupivakain 0,25\% dengan Kombinasi Bupivakain

PG, Cullen BF, Stoelting RK, Cahalan MK, Stock MC, Ortega R, penyunting. Clinical anesthesia. Edisi ke-7. Philadelpia: Lippincott Williams \& Wilkins; 2013. hlm. 1611-44.

8. Brummett CM, Williams BA. Additives to local anesthetics for peripheral nerve blockade. Int Anesthesiol Clin. 2011;49(4):104-16.

9. Gulhas N, Kayhan G, Sanh M, Kitlik A, Durmus M. Effect of adding dexamethasone to bupivacaine on transversus abdominis plane block. Med-Science. 2015;4(4):2732-42.

10. Eltumi HG, Tashani OA. Effect of age, sex and gender on pain sensitivity: a narrative review. TOPAINJ. 2017;10:44-55.

11. Capmbell AL, Yu S, Karia R, Iorio R, Stuchin SA. The effects of body mass index on pain control with liposomal bupivacaine in hip and knee arthroplasty. J Arth. 2017;33(4): 1033-9.

12. Gwam CU, Mistry JB, Mohamed NS, George NE, Etcheson JI, Virani S, dkk. The effect of preoperative physical status on pain management in total knee arthroplasty patients receiving adductor canal blockade. Surg Technol Int. 2017;9(31):897.

13. Macintyre PE, Scott DA, Schug SA, Visser EJ, Walker SM. Physiologi and psychology of acute pain. Dalam: Macintyre PE, Scott DA, Schug SA, Visser EJ, Walker SM, penyunting. Acute pain management: scientivic evidence. Edisi ke 3. Melbourne: Australian and New Zealand College of Anaesthetists; 2010. hlm. 1-33.

14. Fouad HA, Ahmed AMS, Mohammed
Y, Osman M, Abouelmag GMT. Efficacy of preemptive dexamethasone added to bupivacaine in ultrasound guided transversus abdominis plain block for postoperative analgesia after inguinal herniorraphy. AJRC. 2016;4(5):1-16.

15. Yang S, Zhang L. Glucocorticoids and vascular reactivity. Current Vascular Pharmacol. 2004;2(1):1-12.

16. Lin Y, Liu SS. Local anesthetics. Dalam: Barash PG, Cullen BF, Stoelting RK, Cahalan MK, Stock MC, Ortega R, penyunting. Clinical anesthesia. Edisi ke-7. Philadelpia: Lippincott Williams \& Wilkins; 2013. hlm. 561-79.

17. Castillo J, Curley J, Hotz J, Uezono M, Tigner J, Chasin M, dkk. Glucocorticoids prolong rat sciatic nerve blockade in vivo from bupivacaine microspheres. Anesthesiology. 1996;85:1157-66.

18. Ma C, LaMotte RH. Multiple sites for generation of ectopic spontaneous activity in neurone of the chronically compressed dorsal root ganglion. J Neurosci. 2007;27(51):14059-68.

19. Bailard NS, Ortiz J, Flores RA. Additives to local anesthetics for peripheral nerve blockade: evidence, limitations, and recommendations. Am J Health-Syst Pharm. 2014;71:373-83.

20. Macres SM, Moore PG, Fishman SM. Acute pain management. Dalam: Barash PG, Cullen BF, Stoelting RK, Cahalan MK, Stock MC, Ortega R, penyunting. Clinical anesthesia. Edisi ke-7. Philadelpia: Lippincott Williams \& Wilkins; 2013. hlm. 1611-44. 